\title{
EXAMINATION ON POLLUTION CAUSED BY GASOLINE AND DIESEL-FUELED VEHICLES A CASE OF ADAMA, TOWN
}

\author{
Solomon Neway ${ }^{1}$, Ramesh Babu Nallamothu ${ }^{2}$ \\ ${ }^{1}$ Lecturer in Mechanical Engineering Department, Arba Minch University, Arba Minch, \\ Ethiopia. \\ ${ }^{2}$ Mechanical systems \& vehicle engineering program, School of Mechanical Chemical and \\ Materials Engineering, Adama Science and Technology University, Adama, Ethiopia.
}

solomon-neway.jida@ec-nantes.fr, rbnallamothu@gmail.com

\section{ABSTRACT}

The transport sector has an important role to play in the effort to avert the dangerous effects of climate change because it heavily depends on fossil fuels. Currently, most transport related emissions are concentrated in urban areas which account for the largest share of on-road transport energy consumption. It is estimated that transport sources in developing countries contribute about $4 \%$ of the global fossil carbon dioxide versus $18 \%$ by industrialized countries. The cost of urban air pollution is estimated to be $2 \%$ of GDP in developed countries and more than 5\% in developing countries. Adama is one of the old cities in Ethiopia and it is at a distance of $100 \mathrm{~km}$ from capital city of Addis Ababa, Ethiopia. Most of heavy duty truck vehicles in the country are across Adama because of it is corridor of import and export. With an annual vehicle registration and a population growth of over the year, the number of trucks continues to grow exponentially in Adama City. With the increasing urban population and there is an increasing demand for transportation vehicles in Adama necessitating increased air pollution around the city. Most of the minibus vehicles used in Adama has very low energy efficiencies, mainly because they are imported into the country when quite old. The general objective of this study is to examine the pollution caused by gasoline and diesel fueled vehicles in Adama. The measured vehicle emissions have been analyzed in detail. It found that emissions like CO, NOx, HC, PM and $\mathrm{CO}_{2}$ levels are higher than worldwide standards for human and environmental health. The findings indicate the level of pollution is high and will continue to grow if left unabated. Tailpipe emission findings estimated the highest level of NOx emissions at $3.44 \mathrm{~g} / \mathrm{km}, \mathrm{HC}$ emissions at $6.53 \mathrm{~g} / \mathrm{km}, \mathrm{CO}$ at $13.9 \mathrm{~g} / \mathrm{km}, \mathrm{PM} 2.5$ at $1.3 \mathrm{~g} / \mathrm{km}$ and $35.96 \mathrm{~g} / \mathrm{km}$ of $\mathrm{CO}_{2}$. These amounts of emission exceed the proposed draft NEMA ambient air quality emission data and the World Bank ambient air quality guidelines. This implies that persons exposed to these emissions on a daily basis are likely to develop health complications over time as the concentration levels increase. Several mitigation methods can be applied to reduce the emission level such as reduce consumption of fossil fuels and increase efficiency in transport usage of energy. This study confirms that exhaust gases from vehicles pollute Adama's air, and that improperly maintained vehicles contribute significantly to this pollution. It is recommended that a comprehensive motor vehicle pollution control program be designed to implement the proposed NEMA vehicle emission standards. Establishment of an integrated transport system should be made priority to enable the decongestion of Adama city.

Keywords: Greenhouse effect, climate change, mitigation, vehicle emissions standards. 


\section{INTRODUCTION}

Emissions of many air pollutants have been shown to have variety of negative effects on public health and the natural environment. Emissions that are principal pollutants of concern include: hydrocarbons, carbon monoxide $(\mathrm{CO})$, nitrogen oxides $(\mathrm{NOx})$, particulate matter, sulfur oxide (SOx), volatile organic compounds (VOCs). Hydrocarbons are toxins. Hydrocarbons are a major contributor to smog, which can be a major problem in urban areas. Carbon monoxide poisoning is also a major killer [1].

Emission levels are dependent upon many parameter including vehicle-related factors such as model, size, fuel type, technology level and mileage, and operational factors such as speed, acceleration, gear selection, road gradient and ambient temperature [2]. The power to move a car comes from burning fuel in an engine. Pollution from cars comes from by-products of this combustion process (exhaust) and from evaporation of the fuel itself. In the last century, the level of $\mathrm{CO}_{2}$ in the atmosphere has increased by more than $30 \%$ as a result of human activities. The effects of climate change are becoming more pronounced and they include droughts, floods, heat waves and changes in the weather patterns. Global temperatures have increased by almost $0.8^{\circ} \mathrm{C}$ over the past 150 years. Without any global action, it is expected that temperatures will increase further by $1.8-4{ }^{\circ} \mathrm{C}$ by 2100 [3]. It is anticipated that this rise will result in sea level increment of 15 to 95 centimeters. While the transportation sector is crucial to a nation's economy and personal mobility, it is also a significant source of GHGs. Nearly $50 \%$ of global $\mathrm{CO}, \mathrm{HCs}$, and $\mathrm{NOx}$ emissions from fossil fuel combustion come from internal combustion engines (ICE). The contribution of the transport sector to total $\mathrm{CO}_{2}$ emissions in developed nations is forecast to increase from $20 \%$ in 1997 to $30 \%$ in 2020 [4]. The transport sector accounts for almost all the oil demand growth around the world. The world transportation oil demand has continuously risen with increasing Gross domestic product (GDP). World forecasts show that transport oil demand in developing nations will increase three times more than in developed nations. Increasing income will cause a tremendous increase in car ownership in developing countries, where the vehicle stock is expected to triple [5]. Developing countries account for about $10 \%$ of the global automobile population and a little over $20 \%$ of the global transport energy consumption. In comparison, the United States alone consumes about 35\% of the world's transport energy [1].

Road vehicles are among the main consumers of world energy and they dominate global oil utilization, consuming up to $80 \%$ of transport energy. The transport sector's share of oil consumption has been increasing steadily at around $0.6 \%$ per year. Current policies are not sufficient to control road vehicle energy use. Even if governments implement all the measures that are currently being considered, projections by the international energy agency (IEA) show that road vehicle energy use would still rise between now and 2030 at $1.4 \%$ per annum respectively [5]. In developing nations, it is envisaged that with rising income and the rapidly rising mobility that accompanies it, the increase in automobile emissions will be even greater than the developed nations. Steady growth in vehicular populations has put environmental stress on urban centers in various forms particularly causing poor air quality. There is growing evidence that links vehicle pollutants to human ill health. Motor vehicles are major emission sources for several air pollutants, including $\mathrm{NO}_{\mathrm{x}}, \mathrm{CO}, \mathrm{PM}$, and $\mathrm{HCs}$. These pollutants have significant adverse effects on human beings and the environment. Vehicle emissions cause both short and long term problems associated with health effects. For example, HCs and NOx are the precursors of ozone gas, which has effects ranging from short term consequences such as chest 
pain, decreased lung function, and increased susceptibility to respiratory infection, to possible long-term consequences, such as premature lung aging and chronic respiratory illnesses.

The most affected group is the urban inhabitants especially the traffic policemen who are exposed to the fumes for a long period of time [6] compared children attending a school located near a busy way in Utrecht, Netherlands (mean black smoke levels; $53 \mathrm{~g} / \mathrm{m} 3$ ) with children attending a school located in the middle of a green area (mean black smoke levels; $18 \mathrm{~g} / \mathrm{m} 3$ ) in a suburban area. It was discovered that respiratory diseases were more pronounced in the urban than suburban children. The severity of the problem increases when traffic flow is interrupted and the delays and start-stops occur frequently. These phenomena are regularly observed at traffic intersections, junctions and at signalized roadways. Emission rates depend on the characteristics of traffic, vehicles and type of road intersections [7]. The age of a vehicle and maintenance levels also contribute to the emissions of all classes of vehicles. Further, the fuel quality has a direct effect on the vehicular exhaust emissions [8].

Adama is exhibiting high social, economic, structural and change is found to be a fast growing city. Taking into account, Adama fast growth and to enable the transport sector to play its required role, the government has invested a huge resource to construct express way roads Addis to Adama so as to expand the road network. An effort has been made to improve the transport service provisions [9]. There is no integrated planning between agencies of the environmental protection and transport sector. The absence of coordination and symbiosis in implementing the laws and regulations pertinent to environment protection and transport sectors, as well as gaps in improving quality of fuel used in the transportation sector is also a main problem.

A clear understanding of the looming dangers of increased vehicle numbers on the air quality needs to be established [10].

\section{METHDOLOGY}

Measuring the levels of $\mathrm{HC}, \mathrm{CO}, \mathrm{NOx}, \mathrm{CO}_{2}$ and $\mathrm{PM}$ concentrations at three selected Adama sites for thirty-six days and conducting a roadside vehicle inspection by randomly pulling over in-use vehicles to inspect a representative sample of the Adama three wheelers and minibuses fleet are the two major steps in this study. The inspection included; visual inspections of the ECS a measurement of their tailpipe exhaust emissions, on selected vehicles. Interviewing the drivers and obtaining responses for questioners distributed. A questionnaire which was aimed at determining the age of vehicles and mileage and peoples' perceptions on the impact of vehicle emissions was prepared and administered to 50 each minibuses and three wheelers operators. The interviewee sample size was selected based on the availability and co-operation of vehicles operators to respond to the study. The Vehicles were randomly selected based on the age, type and engine model. The experiment was conducted on- road at three areas namely Adama post office, Adama Bus station and Adama Mebrat Haile. By analyzing the advantage and disadvantages of the vehicle pollution measuring techniques, the researcher has chosen a direct on-road emission measurement technique.

\section{RESULTS}

\subsection{Vehicle parc age and mileage}

A total of 240 unique vehicles were tested ranging from model year 1981 to model year 2015, of which $120(50 \%)$ were gasoline-powered and 120 (50\%) were diesel-powered. Among gasoline powered vehicles, $40(33.33 \%)$ were minibuses taxi and 80 (66.67\%) were three wheelers. And from a total of 120 diesel powered vehicles, 60 (50\%) were minibus taxi and the reaming 50\%

were three wheelers taxi. In this study diesel powered vehicles were tested for only particulate matter (PM2.5). The vehicle mileage for minibuses ranged between 15,988 km and 695,910 km 
with an average of $294,703.32 \mathrm{~km}$ and standard deviation of $157,418.6 \mathrm{~km}$. The vehicle mileage for the three wheeler vehicles ranged between $1,111 \mathrm{kM}$ and $67,162 \mathrm{kM}$ with an average of $25,736.1 \mathrm{kM}$ and standard deviation of $16,112.64 \mathrm{kM}$. . Out of the 50 vehicle owners interviewed, $92 \%$ indicated that they had purchased their vehicles from other existing owners. $90 \%$ of the minibuses vehicles lie between 11-32 years indicating that the Adama vehicle parc is quite old but the age of three wheelers lie between 1-8 years. The most common emissions test in I/M programs is a measurement of hydrocarbon and carbon monoxide concentrations in the exhaust while the vehicle is idling. Many inspections in Finland, Germany, Sweden, and the United States supplement this measurement with a second measurement carried out with the engine running at $2500 \mathrm{rpm}$ with no load. The analysis of the emissions from different vehicles showed that $\mathrm{CO}_{2}, \mathrm{CO}, \mathrm{HC}$ and $\mathrm{NOx}$ are released during combustion of fossil fuels. The results obtained are a combination of all the vehicle types considered in the analysis. They cover vehicles with different engine types and sizes. This because of the difficulty involved in accessing vehicles for the experiments. The analysis was done on tail pipe emission

\subsection{HC Emissions}

As show from Figure 1 the level of $\mathrm{HC}$ emissions from all selected vehicle types. The level of $\mathrm{HC}$ emissions observed is highest both idle and 2500rpm operating condition in minibuses.

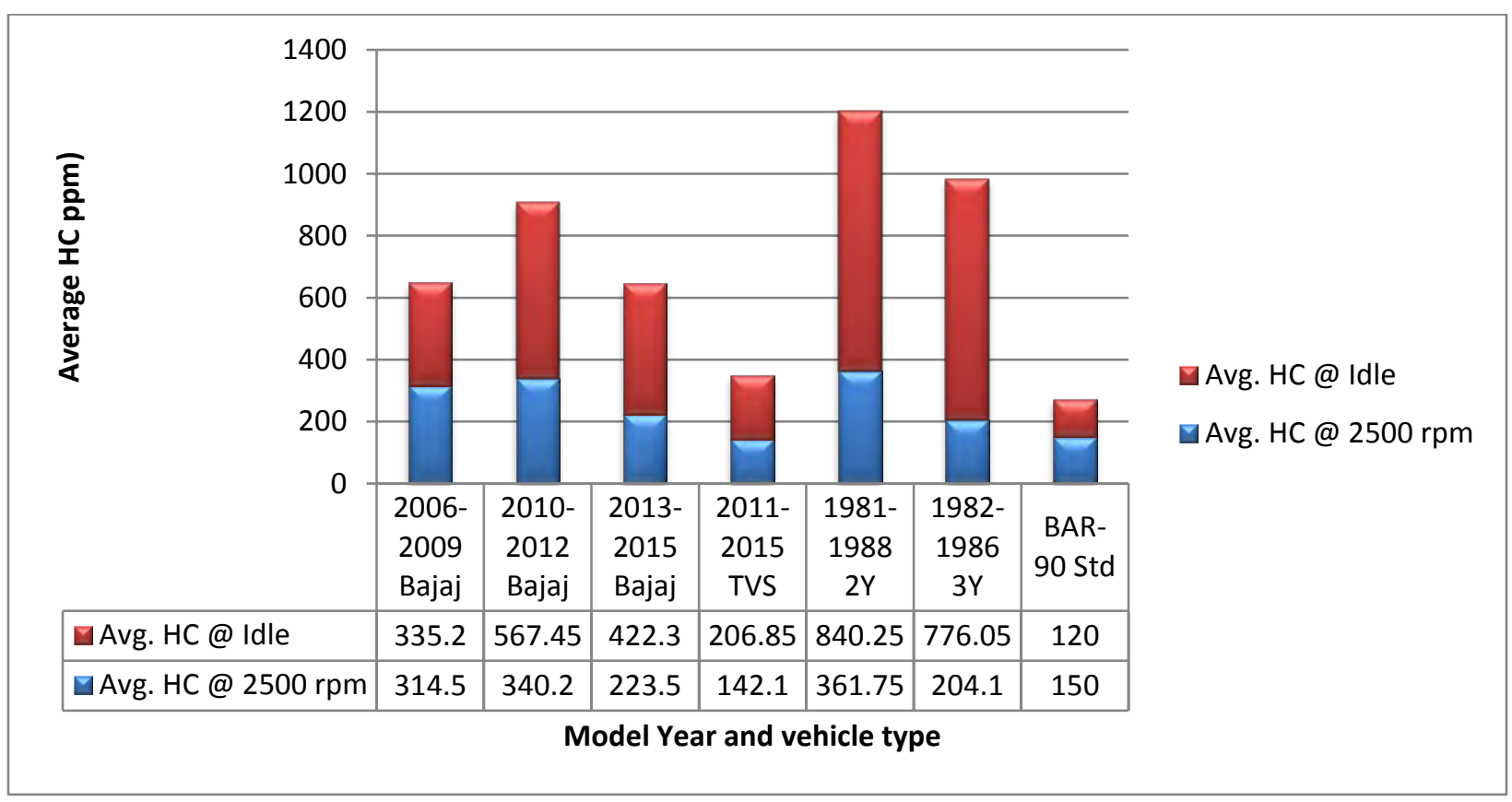

Figure 1: Average Idle/2500 rpm HC Emission

\subsection{CO Emissions}

Emission of carbon monoxide is an indicator of incomplete combustion in the engine. Figure 2 shows the level of carbon monoxide emitted by the three vehicle types. The level of $\mathrm{CO}$ emissions observed is highest both Idle and at $2500 \mathrm{rpm}$ operating condition in three wheelers than Minibuses. 


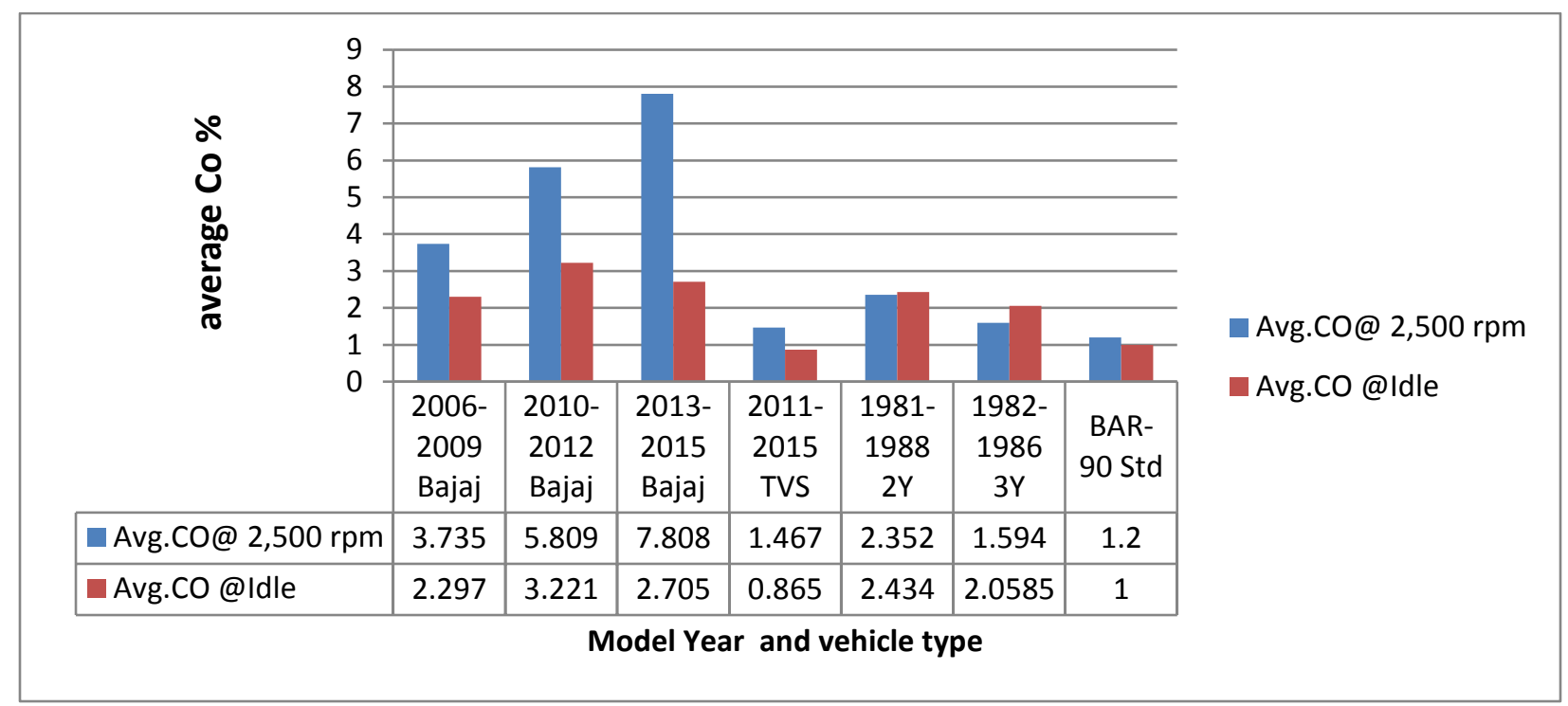

Figure 2: Average $\mathrm{CO}$ at Idle/2500 rpm Emission

\section{4 $\mathrm{CO}_{2}$ Emissions}

From Figure 3, it is observed that the maximum amount of $\mathrm{CO}_{2}$ emitted at free acceleration from the three wheelers Bajaj 2013-15 models and minibus 3Y model, the rest were under the standards. Also, it is observed that the $\mathrm{CO}_{2}$ emission level highest during idle rpm operating condition in the minibuses $3 \mathrm{Y}$ model, the reaming models were under the stated standards.

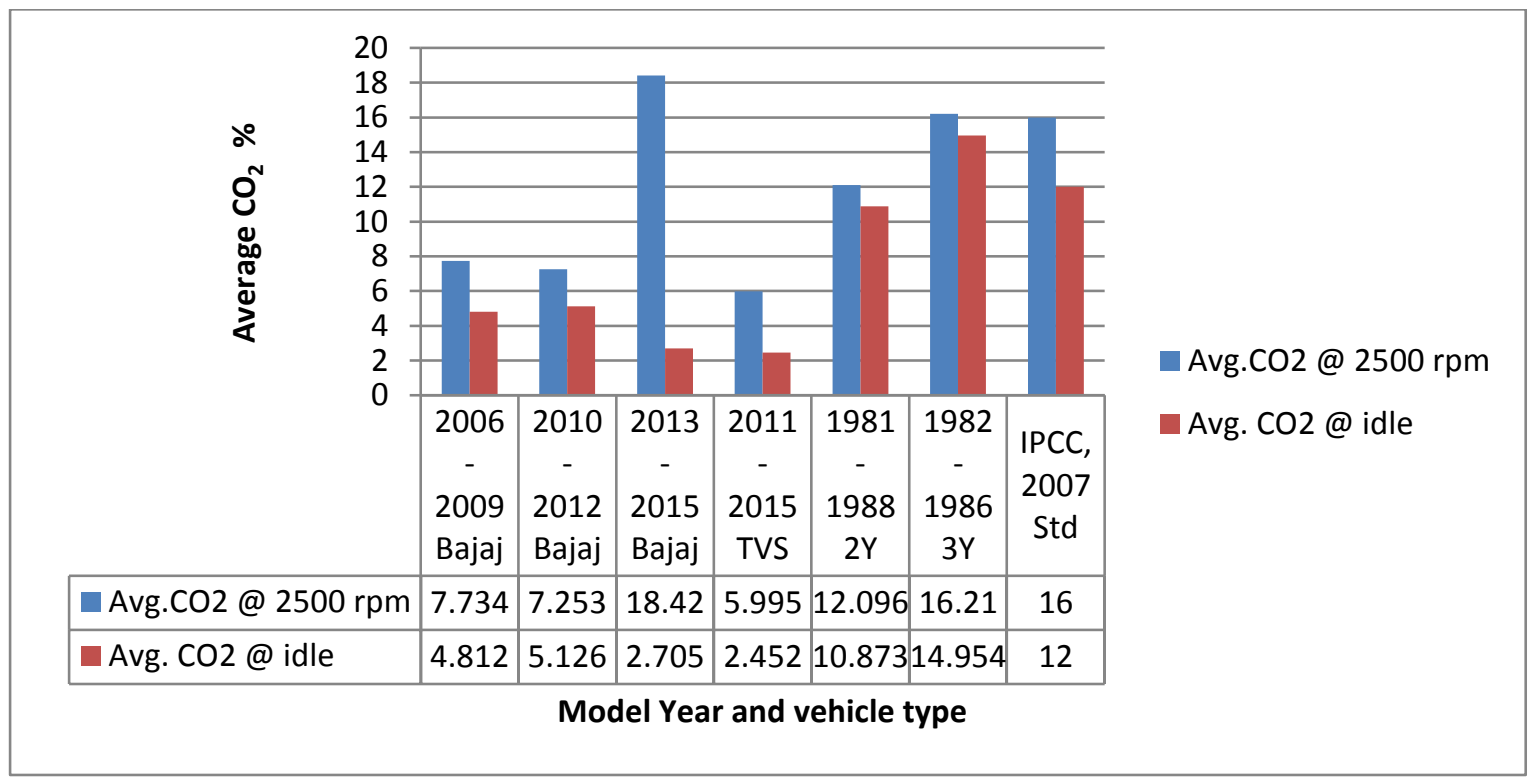

Figure 3: Average $\mathrm{CO}_{2}$ at Idle/2500 rpm emission

\subsection{NOx Emissions}

Figure 4 shows the $\mathrm{NO}_{\mathrm{x}}$ emissions for the different vehicles. The highest level of $\mathrm{NO}_{\mathrm{x}}$ observed was from the minibuses $3 \mathrm{Y}$ at $4.26 \mathrm{ppm}$, minibuses $2 \mathrm{Y}$ at $3.03 \mathrm{ppm}$, three wheelers Bajaj 201315 model at 1.32 ppm, three wheelers Bajaj 2010-12 at 1.24 ppm, and three wheelers Bajaj 200609 model at $1.01 \mathrm{ppm}$ and TVS at $0.73 \mathrm{ppm}$. 


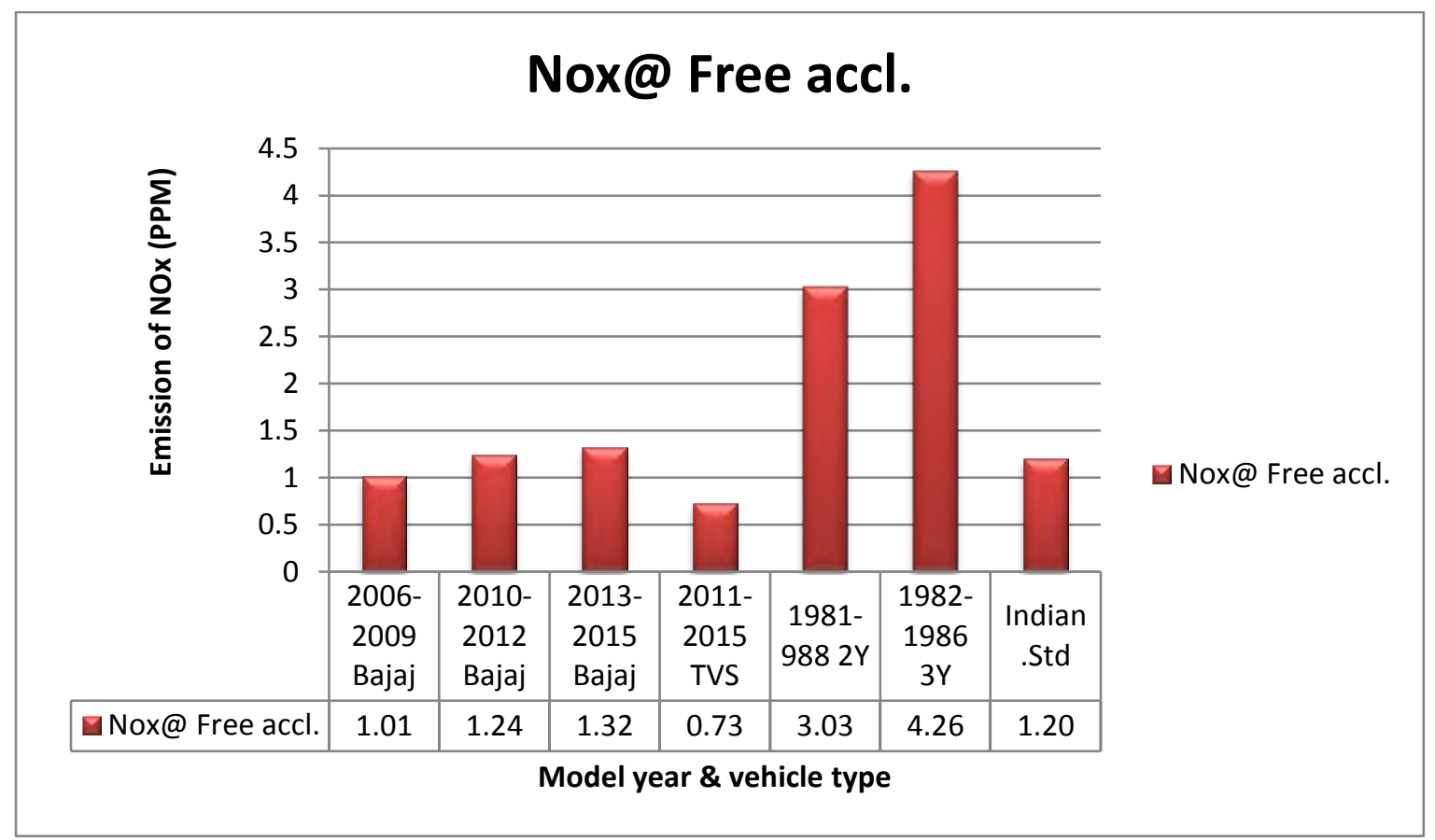

Figure 4: Average $\mathrm{NO}_{\mathrm{x}}$ at free acceleration emission

\subsection{Particulate Matter (PM)}

Figures 5 show the particulate matter readings for three wheelers Force and minibuses $(2 \mathrm{~L}, 3 \mathrm{~L} \&$ 5L) model diesel vehicles, respectively. These graphs show several PM reading values for both vehicles. However, note that there are more emissions for $2 \mathrm{~L}$ at 2.0145 times followed by, 1.74 times, 1.711 times and 1.0375 times 5L, 3L and three wheelers 2006-12 model higher than CARB standards, respectively.

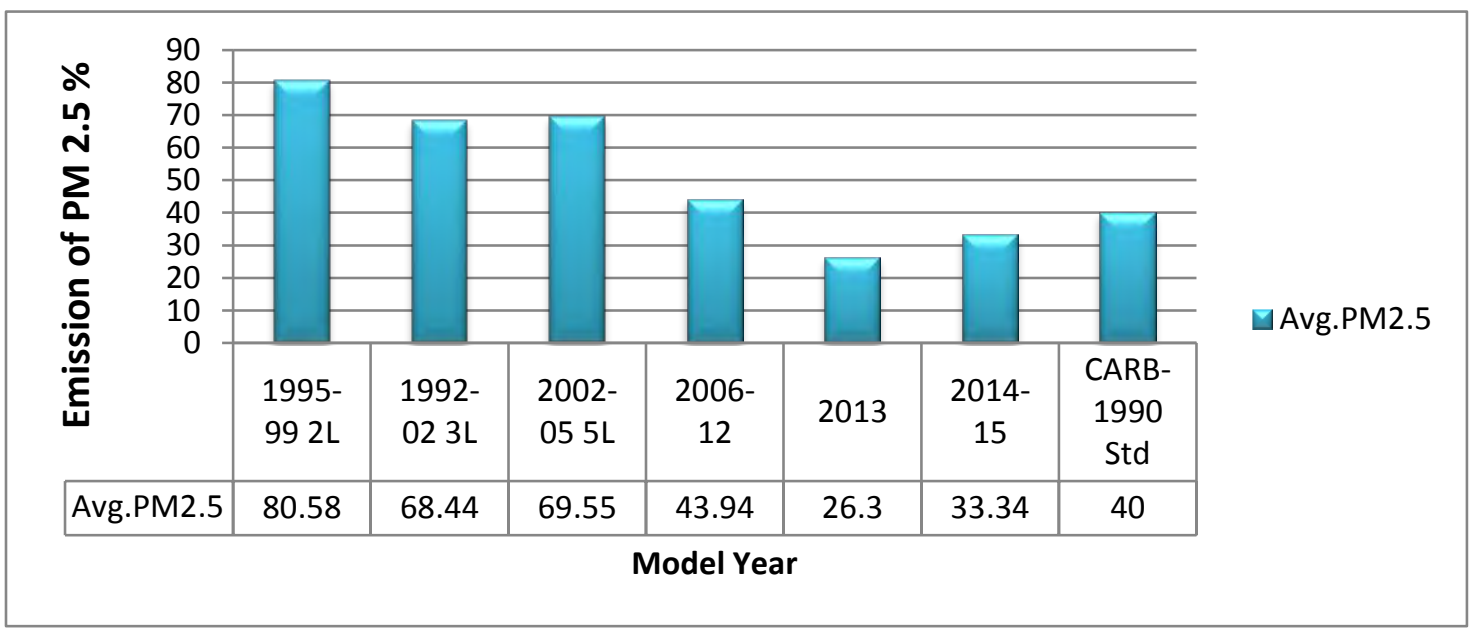

Figure 5: Average $\mathrm{PM}_{2.5}$ at free acceleration

\subsection{Vehicular Emissions Control Systems (ECS's)}

The inspection result shows the various ECS's and the number of vehicles which that have equipped with ECS. Based on the collected data $198(82.5 \%)$ of the inspected vehicles have Positive Crankcase Ventilation (PCV) and 57 (23.75\%) have Thermostatic Air Cleaners (TAC). 


\section{DISCUSSION}

The field survey revealed that most of the minibuses taxis for public transport are imported into the county as second hand overhauled vehicles. The vehicle owners mentioned that at the time of purchase, some of the vehicle mileages were altered to reflect lower mileage indicating that there is a high level of uncertainty in the recorded vehicle mileage data. The impact of the dropping mileage with age is significant in assessing the environment impacts of transport and the potential impact of environment polices. $\mathrm{NO}_{\mathrm{x}}$ and $\mathrm{PM}$ emissions of passenger cars drop by more than $20 \%$ when a decreasing function of mileage with age is used, instead of a fixed mileage for each environment class. Also, the emission contribution from old vehicles decreases which worsens the cost-effectives of air related policy measures targeting such old vehicles [11]. Generally, an excessively high hydrocarbon (due to incomplete combustion) causes carbon monoxide emissions to be high. Hydrocarbon emissions result from spark plug misfires, incorrect ignition timing, wrong air-fuel mixture, etc. These findings further suggest that the lack of regular vehicular preventive maintenance is one of the major aggravators of Adama air pollution.

Emission of carbon monoxide is an indicator of incomplete combustion in the engine. $\mathrm{CO}$ results from spark plug misfires, incorrect ignition timing, and wrong air-fuel mixture etc. Incomplete combustion in the engine due to reduction in the level of oxygen may reflect in more $\mathrm{CO}$ emission. The overall weighted average vehicle tailpipe $\mathrm{CO}$ emissions were $2.7 \%$ and $7.8 \%$, respectively, which is almost equal to the maximum allowable standards for the oldest vehicles (1966-1969) in the California BAR-90 Smog Check program for idle and for $2500 \mathrm{rpm}$.

In generally the tests indicating that $\mathrm{CO}_{2}$ emission levels in three wheelers Bajaj is more compared to both the minibuses vehicles and TVS vehicles. The minibuses emitting more $\mathrm{CO}_{2}$ compared to the TVS vehicles. This is supported by the findings from the survey where vehicles owners were asked how often they carried out maintenance work on their vehicles. Carbon Dioxide $\left(\mathrm{CO}_{2}\right)$ - non-toxic gas but contributes towards acidification of oceans and one of the most important greenhouse gases. Governments around the world are pursuing policies to reduce $\mathrm{CO}_{2}$ emissions to combat global warming.

The $\mathrm{NO}_{\mathrm{x}}$ is formed due to dissociation of molecules when the engine is running hot enough that the oxygen in the air combines with the nitrogen in the air, rather than burning the gasoline. $\mathrm{NO}_{\mathrm{x}}$ emissions were 3Y 4.26 times, 2Y 3.03, Bajaj 2013-15 model 1.1 and Bajaj 2010-12 model 1.033 times higher than the maximum allowable standards for gasoline/gasoline fueled engine in the Indian ARAI-2011emission standards for passenger cars \& light commercial vehicles respectively, which is almost equal to the maximum allowable standards for the oldest vehicles for fixed deterioration factors respectively [12].

The result shows that the vehicle age, mileage, and lack of inspection and regular maintenance were factor for increasing particulate matter emission for the minibuses.

Emissions benefits are only achieved if the PCV, TAC, and other emissions control devices function properly. Although functional checks of the ECS's were not done during the study, it is encouraging to note that most of the tested vehicles had these systems on their engines, which indicates that vehicle (owners) generally do not remove the factory-installed ECS's. 


\section{CONCLUSIONS}

The main aim of this research was to determine the level of pollution from vehicle exhaust gases in Adama. The analysis of emissions was done on three wheelers and public minibuses taxi vehicles which amount to $80 \%$ of the automobile population in Adama city. It was found that emissions from both types of vehicles like $\mathrm{CO}, \mathrm{NO}_{\mathrm{x}}, \mathrm{HC}, \mathrm{PM}$ and $\mathrm{CO}_{2}$ levels are well above worldwide standards for human and environmental health. This indicates that improper functioning and maintenance of causes for pollution from vehicles in Adama. The emissions study has given basic information about emission and vehicle conditions from vehicles were tested. The findings indicate the level of pollution is high and will continue to grow if left unabated. Tail pipe emission findings estimated the highest level of $\mathrm{NO}_{\mathrm{x}}$ emissions at $3.44 \mathrm{~g} / \mathrm{km}$, $\mathrm{HC}$ emissions at $6.53 \mathrm{~g} / \mathrm{km}, \mathrm{CO}$ at $13.9 \mathrm{~g} / \mathrm{km}, \mathrm{PM}_{2.5}$ at $1.3 \mathrm{~g} / \mathrm{km}$ and $35.96 \mathrm{~g} / \mathrm{km}$ of $\mathrm{CO}_{2}$. These amounts exceed the proposed draft NEMA ambient air quality emission data and the World Bank ambient air quality guidelines. This implies that persons exposed to these emissions on a daily basis are likely to develop health complications over time as the concentration levels increase. The potential diseases include lung cancer, bronchitis, cardio vascular diseases and neurobehavioral effects. The reduction in transport emissions can be achieved in two main ways that include reduced consumption of fossil fuels and increased efficiency in transport energy use.

\section{REFERENCES}

[1] K. K. ,. S. F. ,. S. M. ,. Y.-K. Seong Suk Park, «Emission Factors for High-Emitting Vehicles Based on On-Road Measurements of Individual Vehicle Exhaust with a Mobile Measurement Platform," Journal of the Air \& Waste Management Association, 2011.

[2] M. Uganda, «National Transport database,» 2006.

[3] I. I.-G. P. o. ClimateChange, «Guidelines for National Greenhouse Gas Invenories,» Barcknell , USA, 1996.

[4] K. Gwilliam, "Reducing Air Emission from Urban Transport,» The International Bank for Reconstruction and Development, USA, 2004.

[5] L.Cozzi, «Energy and Carbon dioxide Emission Trends in the Transport Sector,» London , 12th January, 2006.

[6] R. A. H. a. G. R. K. Andrew J. Kean, «Effects of Vehicle Speed and Engine Load on Motor Vehicle Emissions, » Environmental Science and Technology, vol. 37, n%117, p. pp 3739-3746, 2003.

[7] s. a. Ghoshal, «www.elsevier.com/locate/trd,» 2009. [En ligne].

[8] G. R., "Vehicle Emission in Relation Fuel Composition," Science of the Total Environment, vol. 169, 
n%17, pp. pp. 149-156, 1995.

[9] C. Agency, «Population Projection Values of 2014 at Zonal and wereds levels by Urban and Resident based,» Addis Ababa, Ethiopia, 2104.

[10] A. Administration, www.Adamacity.gov.et, Ethiopia: Adama , 2015.

[11] C. P. ,. G. L. N. Stefano Caserini, «Impact of the Dropping Activity with Vehicle Age on Air Pollutant Emissions, " Atmospheric Pollution Reserach, vol. 4, n%12013, pp. 282-289, 2013.

[12] A. R. A. o. India, "Indian Emissions Regulations, Limits, Regulations and Measurment of Exahust Emissions and Culculation of fuel Consumption," November 12, 2011.

[13] Stefano Caserini, "Impact of the dropping activity with vehicle age on air pollutant emissions", Atmospheric Pollution Research, 2013.

[14] T. A. R. A. o. India, «Indian Emissions Regulations, limits, Regulations \& Measurment of Exhaust Emissions and Calculation of Fuel Consumption,» ARAI, 2011. 